\title{
Shareholder Wealth Maximization Unde Non-Constant Marginal Cost of Capital: Lifeway Science, Inc. ${ }^{1}$
}

\author{
Robert Stretcher \\ Sam Houston State University • Huntsville, Texas \\ Steve Johnson \\ Sam Houston State University • Huntsville, Texas \\ Mary Funck \\ Sam Houston State University • Huntsville, Texas
}

\section{Introduction}

Traditional capital budgeting methods used in capital expenditure decisions are routinely applied to managerial decisions. Each method has its own strengths and weaknesses, and is often positioned in relation to another in assessments of the validity of the method. The capital expenditure decision is also traditionally thought of as separate from the funding of capital projects; that is, the cost of capital is considered a given in expositions of capital budgeting decision criteria. Most finance textbooks, and indeed, most managers, accept simplifying assumptions in order to avoid the complications associated with a true business environment. For example, while a manager might wish to consider the funding of capital expenditures a separate and distinct decision, funds providers, particularly creditors, certainly consider the two decisions intertwined. In fact, creditors funding capital assets often require specific assets to be pledged as security in order to have a secondary repayment conduit if the primary means of repayment fails.

While the pledging of collateral may not materially affect a capital budgeting decision in some cases, other elements of capital budgeting complexities might. The presence of mutually exclusive projects, projects with unequal lives, and presence of multiple divisions are all possible complicating factors in the decision process. One complexity present in virtually all capital budgeting analyses, yet assumed away or ignored by both finance educators and practicing managers is the presence of nonconstant marginal cost of capital. Assuming some benchmark discount rate for use with capital budgeting techniques may simplify the analysis of projects, but can lead to over- or under-investment, inclusion and exclusion errors, and substantive errors in estimating the shareholder wealth consequences of accepting or rejecting a capital project.

It is difficult to determine a correct business strategy if a key element of the business reality is ignored or assumed away. There are, however, few resources 
available to educators or practicing managers that highlight the decision errors that can result from not recognizing the effects of the non-constant marginal cost of capital. It is in this spirit that anecdotal scenarios, or cases, can be of help to both educators and practicing managers in understanding the proper application of capital budgeting methods.

The case featured in this paper concerns a small company considering five investment projects. The question posed in the case appears simple at first glance: assess the independent projects under consideration and come up with an optimal investment decision. The non-constant marginal cost of capital faced by the company, however, requires a solution that is more complex than decision methods presented in textbooks, usually the case when real business situations are addressed. The reader is tasked with figuring out and performing the appropriate solution, given the typical analytical tools (Excel, and perhaps other software) and time pressures of a professional management environment. The case is appropriate for senior level finance majors, or perhaps administrative problems courses at the MBA level. In a group setting, students should expect to spend 10-20 hours on the solution, depending on the degree of automation they can achieve with analytical software.

\section{Case Assignment For Distribution To Students}

\section{LIFEWAY SCIENCE, INC.: A CAPITAL BUdGETING CHALLENGE}

Nathan Young, a recently hired financial manager for Lifeway Science, Inc. (LSI), had been with the company for only three months. He had been given responsibility for the firm's capital budget for the current year. The Chief Financial Officer (CFO), Natalie Miller (Nathan's direct supervisor), had given Nathan a brief history on her past capital budgeting methods and project selections. Natalie had been the sole financial manager for the firm for the past four years, and had brought in some personal biases four years ago, and had developed several more since. She had emphasized a strong (exclusive?) preference for the Modified Internal Rate of Return (MIRR) method for making the firm's investment decisions. Nathan had listened carefully to her summary and had some records from the past capital budgeting processes.

Nathan had graduated three years prior from a regional state university with a degree in finance, and had gone to work for a community bank in Memphis, Tennessee, first as a credit analyst, and then as a loan officer and Vice President of the 
credit department. He had lost interest in making loans, though, in those three years, and was seeking to find a more challenging (and better paying) career when the position at LSI became available. A friend had referred him to Natalie, and he changed positions last October.

Nathan fully understood the MIRR method and its assumptions. The method assumed that the cashflows from the project would be reinvested at the firm's cost of capital. This differed from the traditional Internal Rate of Return (IRR), which assumed that cashflows from the project were reinvested at the same IRR as the project. This was not a problem when the IRR was sufficiently close to the firm's cost of capital, but problematic for projects with an exceptionally high return, since the likelihood of finding other exceptionally high return projects in which to reinvest was questionable. A 'rate of return' had qualities of both meaning to laypeople (most people understand a percent return) and use as a ranking measure. And the IRR decision rule also considered the required returns of funds providers, unlike the payback period.

The opportunity to apply his academic finance background was appealing, after his three years of performing credit analyses for a lender. Nathan really had no problem with the MIRR method - it was perhaps the best one to use, along with the Net Present Value (NPV) method; he recalled that from his managerial finance courses in college.

\section{LSI Projects}

LSI has several projects under consideration. The sales and cost estimates are already done for these projects, using information from the marketing manager and the firm's internal accountants. The expected net operating cashflows (NOCF's) were estimated based on this information. The first project involves building a $\$ 2.8$ million facility to produce massage tables and chairs, and physical therapy machines. The project has a fifteen year scope. The second project, a ten-year \$1.9 million project, is an equipment update in one of Lifeway's lease facilities. The rental income and costs were provided to Nathan. The third project, a $\$ 1.4$ million project, has a ten-year life. It is also an equipment upgrade. The fourth project is a $\$ 2$ million tenyear project involving the creation of a new lease facility, including a stand-alone building with physical therapy equipment. The lease has already been arranged with a chiropractic group in Memphis. The last project, at $\$ 1.86$ million, is a production facility where electronic monitoring systems would be produced. The exact estimates for net cash inflows and project costs are presented in exhibits 2 through 6 . 
These projects fall into the traditional product/service lines that LSI had been managing for several years, and none of them represents a major expansion for the company. They are all independent, with no contingency or mutual exclusivity.

\section{Capital Costs}

Nathan had been provided with a generic "benchmark" cost of capital figure, $12.3 \%$, which was apparently the extent of the information that had been used in previous capital budgeting analyses. Upon further exploration with the firm's cost accountants, he discovered that this was the same capital cost that had arbitrarily been used for years, with disregard for the equity required returns, bond yields, or lender-specified rates that were prevailing at a given point in time. Nathan began to wonder about the decisions that had been made in the past based on this unchanging capital cost, and being a new analyst, was determined not to fall victim to an unrealistic assumption in this dynamic fundraising environment.

Nathan began to explore the firm's actual current capital cost. He contacted the four commercial banks that the firm appeared to work with on a regular basis. Each lender worked with Nathan to construct a loan appropriate to the risks associated with the overall projects (which were about the same as the firm's existing business). The rates were different for each lender, since each lender faced different subordination of claims to earnings and collateral pledged as security on the loans. Nathan collected commitments from each one for the rates, terms, and limits for their long-term financing alternatives for the firm. He then looked at the going yield for the firm's bonds, and summarized dividend, growth, and pricing information for the firm's stock to estimate internal and external costs of equity financing.

Nathan also looked at the firm's present debt use in comparison to some of the firm's peers. He found that LSI was using about $49 \%$ debt in its capital structure. The peer firms were using substantially more debt, and seemed to be flourishing at the higher level. He also noted that LSI's coverage ratios were more than adequate to sustain payments to creditors, even if the firm adopted greater debt use. He recommended to Natalie that the firm use about $82 \%$ debt for any of the expansion projects currently under consideration, and she was agreeable. Each WACC level in the MCC schedule given in the case is a weighted average of debt (82\%) and equity (18\%) cost. The breakpoints represent the jump in cost as a firm exhausts either a cheaper source of debt or equity (retained earnings). The heavier weight on debt financing was reflected in more pronounced increases in the firms WACC as the cheaper sources were exhausted. The new policy would increase LSI's debt ratio, but would 
still leave it lower than the average for the peer firms, but closer to the average. The implied marginal cost of capital schedule (given the series of breakpoints based on the available retained earnings and four debt limits from the banks) is presented in Exhibit 1.

In his earlier discussion with Natalie, he was told that management had no intention of placing an artificial budget constraint on the investment decisions; any projects that were acceptable would be adopted for investment. It was up to Nathan to demonstrate the attractiveness of the projects, justify his decisions, and manage all of the arrangements for the accepted investments to be undertaken.

\section{Dependence of MIRR and NPV on MCC}

Nathan's belief that using the arbitrary $12.3 \%$ cost of capital was erroneous had the effect of complicating matters. While assuming a constant cost of capital had allowed a fairly simple capital budgeting decision in the past, it had not taken the actual capital costs into account. However, Nathan now realized that his accurate MCC schedule, which increased in a stepwise manner, made a simple decision using the MIRR impossible. The MIRR level depended on the magnitude of the MCC used as the reinvestment rate input. At the same time, he had already agreed with Natalie during his series of interviews that the MIRR was the ideal method to use. Going against that agreement now might cause significant friction between them, friction that Nathan would be causing in reversing his earlier position. His thoughts were focused on this as he drove home.

It was now the evening of December 28th, a Wednesday, and the capital budget was expected at the beginning of January. Nathan decided to analyze the projects as best he could over the coming long weekend; the firm would be closed from December 30th through January 2nd. He poured himself a cup of coffee and walked into his "study" (a corner of his living room). He had kept his advanced financial management book from his undergraduate program. After perusing it for an hour, he came to the conclusion that this particular element of capital budgeting simply had not been covered. The MIRR benefits and drawbacks had been discussed but not in terms of the current business reality facing him: a non-constant marginal cost of capital.

Nathan determined, however, that he would figure out the correct methodology. He reluctantly decided to start with "Natalie's technique" and evaluate each project using the constant cost of capital. Then he could address how critical the error was by using a proper decision method. 


\section{Exhibit 1}

\section{Marginal Cost of Capital Schedule}

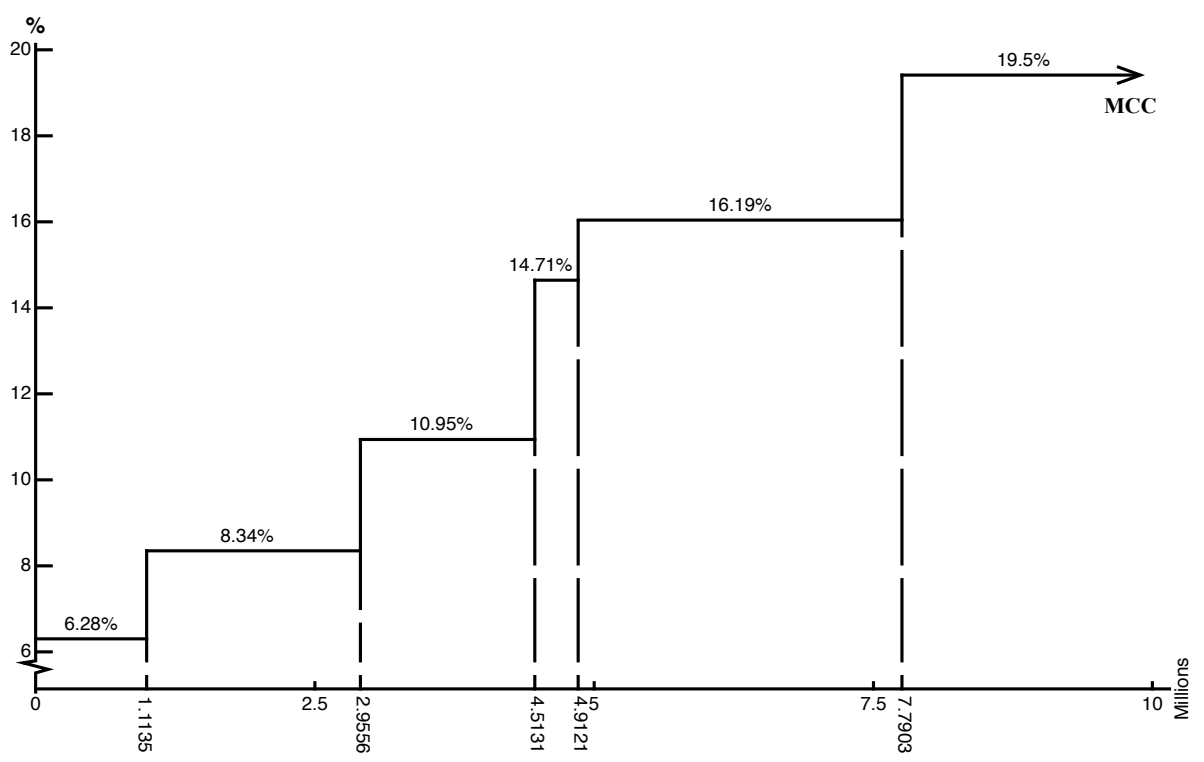

Exhibit 2

Project A Cashflow Estimates

$\begin{array}{cc}\text { Year } & \text { Est. Cashflow } \\ 0 & -\$ 2,794,561.00 \\ 1 & \$ 398,198.00 \\ 2 & \$ 429,472.00 \\ 3 & \$ 419,830.00 \\ 4 & \$ 406,287.00 \\ 5 & \$ 400,190.00 \\ 6 & \$ 397,287.00 \\ 7 & \$ 390,844.00 \\ 8 & \$ 385,924.00 \\ 9 & \$ 381,955.00 \\ 10 & \$ 376,921.00 \\ 11 & \$ 371,438.00 \\ 12 & \$ 361,847.00 \\ 13 & \$ 348,730.00 \\ 14 & \$ 309,177.00 \\ 15 & \$ 278,276.00\end{array}$


Exhibit 3

Project B Cashflow Estimates

$\begin{array}{cc}\text { Year } & \text { Est. Cashflow } \\ 0 & -\$ 1,900,250.00 \\ 1 & \$ 398,291.00 \\ 2 & \$ 402,389.00 \\ 3 & \$ 393,839.00 \\ 4 & \$ 391,112.00 \\ 5 & \$ 387,340.00 \\ 6 & \$ 379,004.00 \\ 7 & \$ 374,854.00 \\ 8 & \$ 369,789.00\end{array}$

\section{Exhibit 5}

\section{Project D Cashflow Estimates}

$\begin{array}{cc}\text { Year } & \text { Est. Cashflow } \\ 0 & -\$ 1,933,980.00 \\ 1 & \$ 365,990.00 \\ 2 & \$ 360,980.00 \\ 3 & \$ 358,276.00 \\ 4 & \$ 349,999.00 \\ 5 & \$ 345,090.00 \\ 6 & \$ 239,856.00 \\ 7 & \$ 334,856.00 \\ 8 & \$ 329,377.00 \\ 9 & \$ 320,002.00 \\ 10 & \$ 319,897.00\end{array}$

Exhibit 4

Project C Cashflow Estimates

$\begin{array}{cc}\text { Year } & \text { Est. Cashflow } \\ 0 & -\$ 1,394,527.00 \\ 1 & \$ 0.00 \\ 2 & \$ 0.00 \\ 3 & \$ 399,789.00 \\ 4 & \$ 379.837 .00 \\ 5 & \$ 368,471.00 \\ 6 & \$ 352,909.00 \\ 7 & \$ 332,746.00 \\ 8 & \$ 321,736.00 \\ 9 & \$ 313,808.00 \\ 10 & \$ 301,548.00\end{array}$

Exhibit 6

Project E Cashflow Estimates

$\begin{array}{cccc}\text { Year } & \text { Est. Cashflow } & 13 & \$ 360,158.00 \\ 0 & -\$ 1,856,945.00 & 14 & \$ 358,613.00 \\ 1 & \$ 0.00 & 15 & \$ 335,123.00 \\ 2 & \$ 0.00 & 16 & \$ 352,197.00 \\ 3 & \$ 0.00 & 17 & \$ 350,088.00 \\ 4 & \$ 0.00 & 18 & \$ 345,987.00 \\ 5 & \$ 362,994.00 & 19 & \$ 340,127.00 \\ 6 & \$ 389,089.00 & 20 & \$ 334,157.00 \\ 7 & 4385,412.00 & 21 & \$ 328,657.00 \\ 8 & \$ 380,189.00 & 22 & \$ 320,121.00 \\ 9 & \$ 375,189.00 & 23 & \$ 312,599.00 \\ 10 & \$ 371,254.00 & 24 & \$ 304,572.00 \\ 11 & \$ 368,534.00 & 25 & \$ 299,099.00 \\ 12 & \$ 366,259.00 & 26 & \$ 294,948.00\end{array}$




\section{Teaching Note}

Under Natalie's unrealistic simplifying assumption of a constant marginal cost of capital across the range of investment at a point in time, it is easy to initiate a simple mechanical process for calculating net present values and modified internal rates of return, since both are dependent on the cost of capital as an input. Unfortunately, the assumption is very likely to result in suboptimal capital budgeting decisions, as in this case. In Exhibit TN1 the IRR, MIRR, NPV, and acceptance decisions associated with using Natalie's "benchmark" cost of capital are presented.

\section{Exhibit TN1}

Constant Cost of Capital

Total NPV using Constant Cost of Capital

$\begin{array}{cccccc}\text { Project } & \text { IRR } & \text { NPV } & \text { MIRR } & \text { Accept } & \text { Total NPV } \\ \text { A } & 11.11 \% & (\$ 166,108) & 11.84 \% & \text { No } & \$ 0 \\ \text { B } & 12.54 \% & \$ 15,921 & 12.42 \% & \text { Yes } & \$ 15,921 \\ \text { C } & 12.14 \% & (\$ 11,249) & 12.21 \% & \text { No } & \$ 0 \\ \text { D } & 11.08 \% & (\$ 94,200) & 11.76 \% & \text { No } & \$ 0 \\ \text { E } & 11.76 \% & (\$ 99,651) & 12.09 \% & \text { No } & \$ 0\end{array}$

A constant marginal cost of capital, however, would seldom describe the actual fundraising costs faced by a firm at any given point in time; instead, firms generally line up financing for their capital budget where convenient, usually from multiple sources. This is the case for LSI. Each WACC level in the MCC schedule given in the case is a weighted average of debt (82\%) and equity (18\%) cost. The breakpoints represent the jump in cost as a firm exhausts either a cheaper source of debt or equity (retained earnings). In order to emphasize the error associated with using Natalie's benchmark, the breakpoints have been exaggerated in comparison to the actual breakpoints encountered by the disguised subject firm.

The IRR method is fairly straightforward, as its calculation is independent of the firm's cost of capital. The IRR solution, though, would result in a sub-optimal solution (shown in Exhibit TN2), since the NPV of the order of projects implied by the IRR is only $\$ 659,710.52$, accepting projects $\mathrm{B}$ and $\mathrm{C}$ according to the investment opportunity schedule (IOS) in figure 1. 


\section{Exhibit TN2}

\section{Figure 1}

\section{Marginal Cost of Capital and Investment Opportunity Schedule Superimposed}

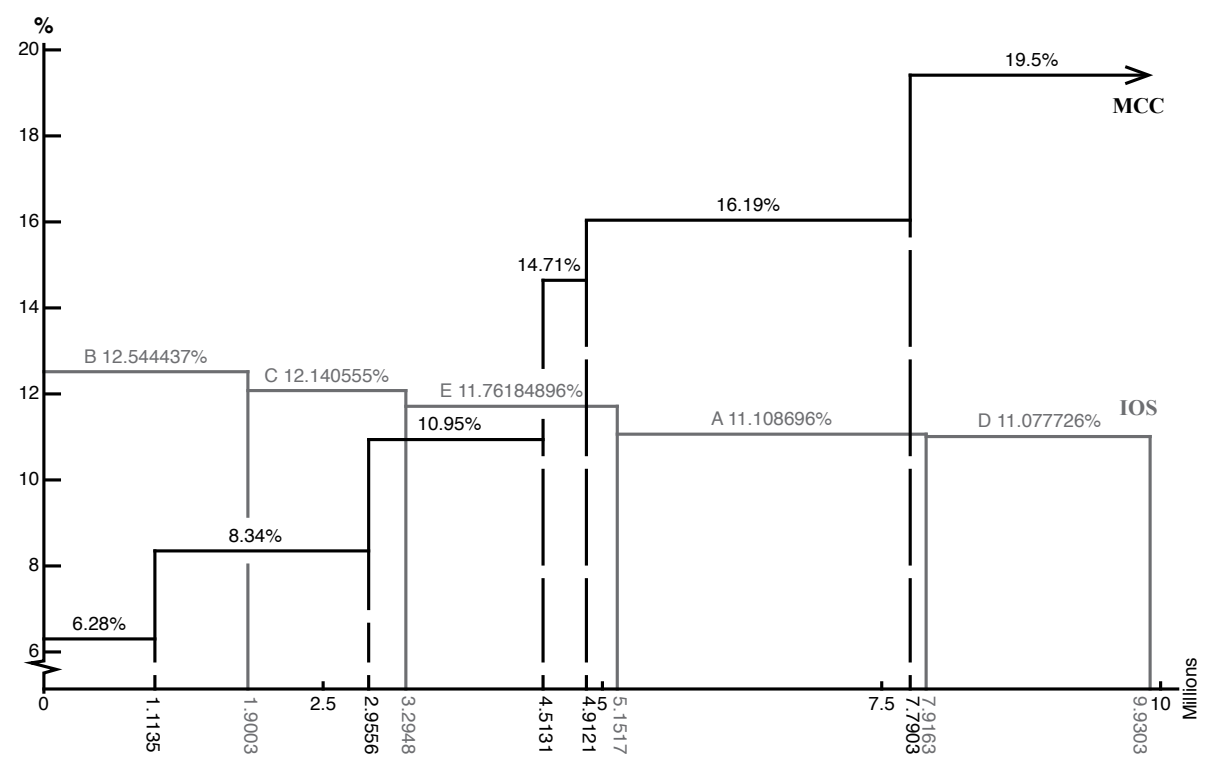

The projects are presented in order of attractiveness according to the IRR. Projects B and C are accepted, since their IRR's exceed the MCC throughout the scope of investment (up to $\$ 3,294,777$ ) and Projects A and D are rejected since the MCC exceeds their respective IRRs. The decision on project E, however, is less clear since its spans one MCC level below and two levels above its IRR. The marginal project is evaluated using the appropriate weighted MCC:

$$
\begin{aligned}
& w M C C=\left(\frac{\$ 4,513,100-3,294,777}{\$ 1,856,945}\right)(10.95)+ \\
& \qquad\left(\frac{\$ 4,912,100-4,513,100}{\$ 1,856,945}\right)(1471)+\left(\frac{\$ 5,151,722-4,912,100}{\$ 1,856,945}\right)(16.1 \\
& w M C C=12.434 \%
\end{aligned}
$$


Since the weighted MCC for project E exceeds the IRR of $11.762 \%$, the project is rejected. In some cases, the IRR decision might represent shareholder wealth maximization. The maximum NPV selection, though, is the optimal decision.

In this case, the total NPV associated with the IRR decision is $\$ 659,710.95$ for accepting projects B and C (using appropriate MCC inputs of .071329 and .089748 for projects $\mathrm{B}$ and $\mathrm{C}$, respectively). The net present value for the remaining possible permutations must be determined for the accepted projects for each permutation to determine if it is the true optimal capital budget.

A rather cumbersome technicality, however, for using either net present value (NPV), or modified internal rate of return (MIRR), is that these require the project's marginal cost of capital (MCC) as an input. The order of presentation, as well as the combination of projects, is necessary to consider, since projects ordered first are assessed using lower MCC averages than those ordered subsequently. Reinvestment of cash flows at the appropriate MCC often creates profound differences in project NPV based on the rank ordering.

To illustrate, suppose we select a different order of projects than the order shown in Exhibit 1, (E A B C D). The net present value (or the MIRR) can be calculated using the weighted MCC for each project, and then the NPV's for the accepted projects totaled. For this permutation, the IOS changes:

\section{Figure 2}

\section{Marginal Cost of Capital and Investment Opportunity Schedule Superimposed}

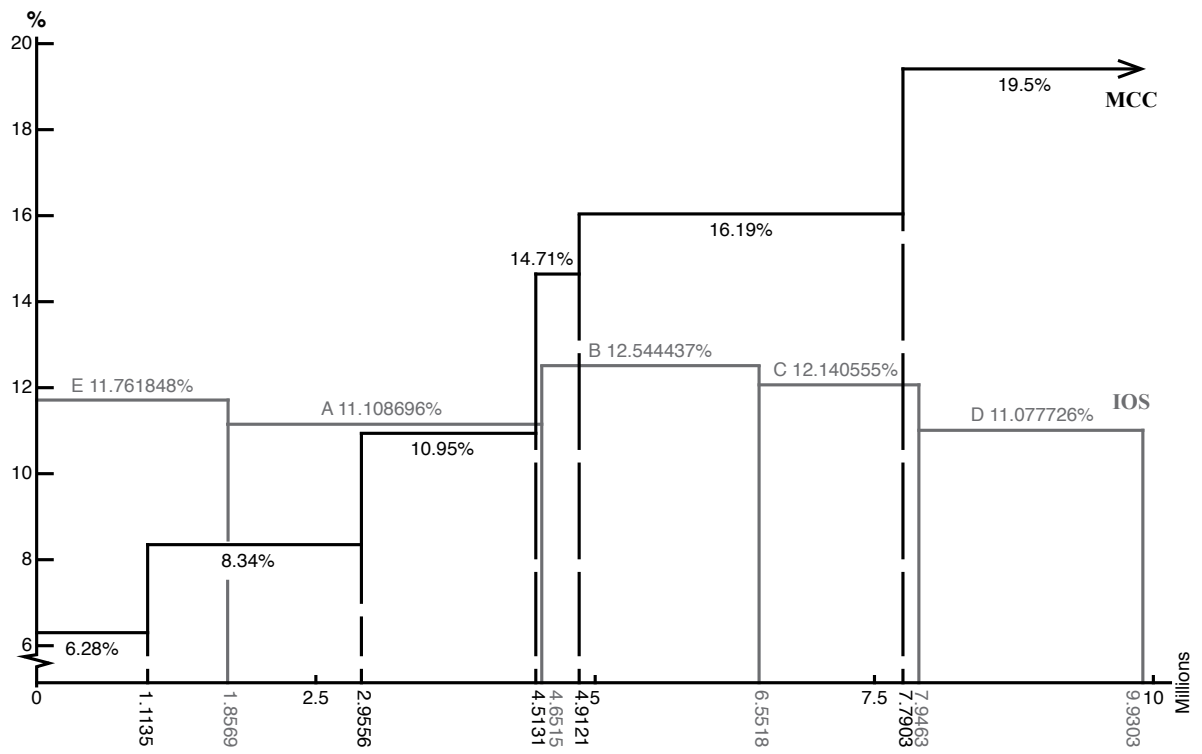


In Figure 2, the IOS is superimposed on the MCC with the EABCD rank ordering. It is interesting to note that the IRR (the height of each project) is always irrelevant when determining the NPV. The inputs that matter are the cashflows of each project (including the initial cash outflow as the width of each project) and the appropriate WMCC applied to each project. In this case, the total NPV associated with this permutation is $\$ 1,441,440.44$ for accepting projects $\mathrm{E}$ and $\mathrm{A}$ (using appropriate WMCC inputs of .0710474 and 101101246 for projects $\mathrm{E}$ and A, respectively).

Note that the NPV associated with accepting projects E and A exceeds both that of the IRR decision and the decision implied by using Natalie's "benchmark" method. Neither of the two permutations exhibited above, however, represents the maximum NPV solution. To be certain of a maximum NPV solution, the calculation must be repeated for all possible permutations.

There are several possible approaches to solution of the dilemma. First, a manual approach could be used - rather cumbersome, given that there are 120 (5!) possible permutations, but certainly an alternative, especially since students may not be familiar enough with programming to automate the process. Second, there are various alternatives for producing a programmed solution. Students with good programming backgrounds in Excel can create solutions for each permutation and select the maximum NPV result. More sophisticated processes can be created using Visual Basic or other programming languages. A combination could also be used, such as using the Visual Basic add-in in conjunction with Excel spreadsheets.

The analytical output, regardless of the process to handle calculations, is a net present value associated with each possible permutation. The NPV solution for each appears in Tables $1 \mathrm{a}, 1 \mathrm{~b}$, and $1 \mathrm{c}$. The maximum NPV solution is $\$ 1,555,930.02$, highlighted in table 1c for the two permutations tied for highest NPV (ECBAD and ECBDA). In either case, projects E, C, and B are accepted and projects A and D are rejected. To check students' work, tables $1 \mathrm{a}, 1 \mathrm{~b}$, and $1 \mathrm{c}$ can be referenced. The detail for the optimal solution appears in exhibit TN3. 


\section{Exhibit TN3}

\section{(Rank order 1,2,3,4,and 5 corresponds to projects $A, B, C, D$ and $E$ respectively)}

$\begin{array}{lccrrr}\text { Permutations: } & 5,3,2,1,4 & \text { Project } & \text { Investment } & \text { MWACC } & \text { NPV } \\ & 5 & \$ 1,856,945 & 7.10 \% & \$ 1,288,636.62 \\ & 3 & \$ 1,394,527 & 8.89 \% & \$ 257,928.56 \\ & 2 & \$ 1,900,250 & 12.40 \% & \$ 9,364.84 \\ & 1 & \$ 2,794,561 & 16.37 \% & \$ 0.00 \\ & 4 & \$ 1,983,980 & 19.50 \% & \$ 0.00\end{array}$

Total NPV. $\$ 1,555,930.02$

Optimal Investment: $\$ 5,1561,722.00$

\begin{tabular}{|c|c|c|c|c|c|}
\hline \multirow[t]{6}{*}{ Permutations: } & \multirow[t]{6}{*}{$5,3,2,4,1$} & Project & Investment & MWACC & NPV \\
\hline & & 5 & $\$ 1,856,945$ & $7.10 \%$ & $\$ 1,288,636.62$ \\
\hline & & 3 & $\$ 1,394,527$ & $8.89 \%$ & $\$ 257,928.56$ \\
\hline & & 2 & $\$ 1,900,250$ & $12.40 \%$ & $\$ 9,364.84$ \\
\hline & & 4 & $\$ 1,983,980$ & $16.19 \%$ & $\$ 0.00$ \\
\hline & & 1 & $\$ 2,794,561$ & $18.72 \%$ & $\$ 0.00$ \\
\hline
\end{tabular}

Optimal Investment: $\$ 5,1561,722.00$ 
Table 1a

NPV's for permutations 1-40

(Rank order 1,2,3,4,and 5 corresponds to projects A,B,C,D and E respectively)

\begin{tabular}{|c|c|c|c|}
\hline Permutation & $\begin{array}{l}\text { Rank } \\
\text { Order }\end{array}$ & Total NPV & $\begin{array}{c}\text { Accepted } \\
\text { Projects }\end{array}$ \\
\hline 1 & 12345 & $\$ 716,266,53$ & $A, B$ \\
\hline 2 & 12354 & $\$ 716,266,53$ & $A, B$ \\
\hline 3 & 12435 & $\$ 716,266,53$ & $A, B$ \\
\hline 4 & 12453 & $\$ 716,266,53$ & $A, B$ \\
\hline 5 & 12534 & $\$ 716,266,53$ & $A, B$ \\
\hline 6 & 12543 & $\$ 716,266,53$ & $A, B$ \\
\hline 7 & 13245 & $\$ 729,569.15$ & $A, C$ \\
\hline 8 & 13254 & $\$ 729,569.15$ & $A, C$ \\
\hline 9 & 13425 & $\$ 729,569.15$ & $A, C$ \\
\hline 10 & 13452 & $\$ 729,569.15$ & $A, C$ \\
\hline 11 & 13524 & $\$ 729,569.15$ & $A, C$ \\
\hline 12 & 13542 & $\$ 729,569.15$ & $A, C$ \\
\hline 13 & 14235 & $\$ 618,196.45$ & $A$ \\
\hline 14 & 14253 & $\$ 618,196.45$ & $A$ \\
\hline 15 & 14325 & $\$ 618,196.45$ & $A$ \\
\hline 16 & 14352 & $\$ 618,196.45$ & $A$ \\
\hline 17 & 14523 & $\$ 618,196.45$ & A \\
\hline 18 & 14532 & $\$ 618,196.45$ & A \\
\hline 19 & 15234 & $\$ 771,921.60$ & $A, E$ \\
\hline 20 & 15243 & $\$ 771,921.60$ & $A, E$ \\
\hline 21 & 15324 & $\$ 771,921.60$ & $A, E$ \\
\hline 22 & 15342 & $\$ 771,921.60$ & $A, E$ \\
\hline 23 & 15423 & $\$ 771,921.60$ & $A, E$ \\
\hline 24 & 15432 & $\$ 771,921.60$ & $A, E$ \\
\hline 25 & 21345 & $\$ 546,060.29$ & $B, A$ \\
\hline 26 & 21354 & $\$ 546,060.29$ & $\mathrm{~B}, \mathrm{~A}$ \\
\hline 27 & 21435 & $\$ 546,060.29$ & $B, A$ \\
\hline 28 & 21453 & $\$ 546,060.29$ & $\mathrm{~B}, \mathrm{~A}$ \\
\hline 29 & 21534 & $\$ 546,060.29$ & $B, A$ \\
\hline 30 & 21543 & $\$ 546,060.29$ & $B, A$ \\
\hline 31 & 23145 & $\$ 659,710.52$ & $B, C$ \\
\hline 32 & 23154 & $\$ 659,710.52$ & $B, C$ \\
\hline 33 & 23415 & $\$ 659,710.52$ & $B, C$ \\
\hline 34 & 23451 & $\$ 659,710.52$ & $B, C$ \\
\hline 35 & 23514 & $\$ 659,710.52$ & $B, C$ \\
\hline 36 & 23541 & $\$ 659,710.52$ & $B, C$ \\
\hline 37 & 24135 & $\$ 536,727.67$ & $B, D$ \\
\hline 38 & 24153 & $\$ 536,727.67$ & $B, D$ \\
\hline 39 & 24315 & $\$ 536,727.67$ & $B, D$ \\
\hline 40 & 24351 & $\$ 536,727.67$ & $B, D$ \\
\hline
\end{tabular}


Table 1b

NPV's for permutations 41-80

\begin{tabular}{|c|c|c|c|}
\hline Permutation & $\begin{array}{l}\text { Rank } \\
\text { Order }\end{array}$ & Total NPV & $\begin{array}{c}\text { Accepted } \\
\text { Projects }\end{array}$ \\
\hline 41 & 24513 & $\$ 536,727.67$ & $B, D$ \\
\hline 42 & 24531 & $\$ 536,727.67$ & $B, D$ \\
\hline 43 & 25134 & $\$ 931,421.00$ & $B, E$ \\
\hline 44 & 25143 & $\$ 931,421.00$ & $B, E$ \\
\hline 45 & 25314 & $\$ 931,421.00$ & $B, E$ \\
\hline 46 & 25341 & $\$ 931,421.00$ & $B, E$ \\
\hline 47 & 25413 & $\$ 931,421.00$ & $B, E$ \\
\hline 48 & 25431 & $\$ 931,421.00$ & $B, E$ \\
\hline 49 & 31245 & $\$ 723,519.16$ & $C, A$ \\
\hline 50 & 31254 & $\$ 723,519.16$ & $\mathrm{C}, \mathrm{A}$ \\
\hline 51 & 31425 & $\$ 723,519.16$ & $\mathrm{C}, \mathrm{A}$ \\
\hline 52 & 31452 & $\$ 723,519.16$ & $\mathrm{C}, \mathrm{A}$ \\
\hline 53 & 31524 & $\$ 723,519.16$ & $\mathrm{C}, \mathrm{A}$ \\
\hline 54 & 31542 & $\$ 723,519.16$ & $\mathrm{C}, \mathrm{A}$ \\
\hline 55 & 32145 & $\$ 738,071.12$ & C, B \\
\hline 56 & 32154 & $\$ 738,071.12$ & C, B \\
\hline 57 & 32415 & $\$ 738,071.12$ & $\mathrm{C}, \mathrm{B}$ \\
\hline 58 & 32451 & $\$ 738,071.12$ & $\mathrm{C}, \mathrm{B}$ \\
\hline 59 & 32514 & $\$ 738,071.12$ & C, B \\
\hline 60 & 32541 & $\$ 738,071.12$ & $\mathrm{C}, \mathrm{B}$ \\
\hline 61 & 34125 & $\$ 657,310.59$ & $C, D$ \\
\hline 62 & 34152 & $\$ 657,310.59$ & C, D \\
\hline 63 & 34215 & $\$ 657,310.59$ & $C, D$ \\
\hline 64 & 34251 & $\$ 657,310.59$ & $C, D$ \\
\hline 65 & 34512 & $\$ 657,310.59$ & C, D \\
\hline 66 & 34521 & $\$ 657,310.59$ & C, D \\
\hline 67 & 35124 & $\$ 1,193,210.45$ & $C, E$ \\
\hline 68 & 35142 & $\$ 1,193,210.45$ & $C, E$ \\
\hline 69 & 35214 & $\$ 1,202,575.52$ & $C, E, B$ \\
\hline 70 & 35241 & $\$ 1,202,575.52$ & $C, E, B$ \\
\hline 71 & 35412 & $\$ 1,193,210.45$ & $C, E$ \\
\hline 72 & 35421 & $\$ 1,193,210.45$ & $C, E$ \\
\hline 73 & 41235 & $\$ 463,466.52$ & $\mathrm{D}, \mathrm{A}$ \\
\hline 74 & 41253 & $\$ 463,466.52$ & $\mathrm{D}, \mathrm{A}$ \\
\hline 75 & 41325 & $\$ 463,466.52$ & $D, A$ \\
\hline 76 & 41352 & $\$ 463,466.52$ & $D, A$ \\
\hline 77 & 41523 & $\$ 463,466.52$ & $D, A$ \\
\hline 78 & 41532 & $\$ 463,466.52$ & $\mathrm{D}, \mathrm{A}$ \\
\hline 79 & 42135 & $\$ 562,033.60$ & $\mathrm{D}, \mathrm{B}$ \\
\hline 80 & 42153 & $\$ 562,033.60$ & $\mathrm{D}, \mathrm{B}$ \\
\hline
\end{tabular}


Table 1c

NPV's for permutations 81-120.

\begin{tabular}{|c|c|c|c|}
\hline Permutation & $\begin{array}{l}\text { Rank } \\
\text { Order }\end{array}$ & Total NPV & $\begin{array}{c}\text { Accepted } \\
\text { Projects }\end{array}$ \\
\hline 81 & 24513 & $\$ 562,033.60$ & $\overline{D, B}$ \\
\hline 82 & 24531 & $\$ 562,033.60$ & $\mathrm{D}, \mathrm{B}$ \\
\hline 83 & 25134 & $\$ 562,033.60$ & $D, B$ \\
\hline 84 & 25143 & $\$ 562,033.60$ & $\mathrm{D}, \mathrm{B}$ \\
\hline 85 & 25314 & $\$ 593,337.54$ & $D, C$ \\
\hline 86 & 25341 & $\$ 593,337.54$ & $D, C$ \\
\hline 87 & 25413 & $\$ 593,337.54$ & $D, C$ \\
\hline 88 & 25431 & $\$ 593,337.54$ & $D, C$ \\
\hline 89 & 31245 & $\$ 593,337.54$ & $D, C$ \\
\hline 90 & 31254 & $\$ 593,337.54$ & $\mathrm{D}, \mathrm{C}$ \\
\hline 91 & 31425 & $\$ 847,501.24$ & $\mathrm{D}, \mathrm{E}$ \\
\hline 92 & 31452 & $\$ 847,501.24$ & $\mathrm{D}, \mathrm{E}$ \\
\hline 93 & 31524 & $\$ 847,501.24$ & $\mathrm{D}, \mathrm{E}$ \\
\hline 94 & 31542 & $\$ 847,501.24$ & $\mathrm{D}, \mathrm{E}$ \\
\hline 95 & 32145 & $\$ 847,501.24$ & $D, E$ \\
\hline 96 & 32154 & $\$ 847,501.24$ & $\mathrm{D}, \mathrm{E}$ \\
\hline 97 & 32415 & $\$ 1,441,440.43$ & $E, A$ \\
\hline 98 & 32451 & $\$ 1,441,440.43$ & $E, A$ \\
\hline 99 & 32514 & $\$ 1,441,440.43$ & $E, A$ \\
\hline 100 & 32541 & $\$ 1,441,440.43$ & $E, A$ \\
\hline 101 & 34125 & $\$ 1,441,440.43$ & E, A \\
\hline 102 & 34152 & $\$ 1,441,440.43$ & $E, A$ \\
\hline 103 & 34215 & $\$ 1,507,687.79$ & E, B \\
\hline 104 & 34251 & $\$ 1,507,687.79$ & E, B \\
\hline 105 & 34512 & $\$ 1,507,687.79$ & E, B \\
\hline 106 & 34521 & $\$ 1,507,687.79$ & $E, B$ \\
\hline 107 & 35124 & $\$ 1,507,687.79$ & E, B \\
\hline 108 & 35142 & $\$ 1,507,687.79$ & E, B \\
\hline 109 & 35214 & $\$ 1,546,565.18$ & E, C \\
\hline 100 & 35241 & $\$ 1,546,565.18$ & $E, C$ \\
\hline 111 & 35412 & $\$ 1,555,930.02$ & $E, C, B$ \\
\hline 112 & 35421 & $\$ 1,555,930.02$ & $E, C, B$ \\
\hline 113 & 41235 & $\$ 1,546,565.18$ & $E, C$ \\
\hline 114 & 41253 & $\$ 1,546,565.18$ & E, C \\
\hline 115 & 41325 & $\$ 1,421,464.95$ & E, D \\
\hline 116 & 41352 & $\$ 1,421,464.95$ & $E, D$ \\
\hline 117 & 41523 & $\$ 1,421,464.95$ & E, D \\
\hline 118 & 41532 & $\$ 1,421,464.95$ & $E, D$ \\
\hline 119 & 42135 & $\$ 1,421,464.95$ & $E, D$ \\
\hline 120 & 42153 & $\$ 1,421,464.95$ & $E, D$ \\
\hline
\end{tabular}




\section{Communication and Protocol Issue in the Case}

One element of the case that professors may want to stress is that, after the analysis of the possible permutations is complete and the maximum NPV choice clear, it is still Nathan's responsibility to report his findings in a, let's say, "politically sensitive" way, to Natalie Miller (Nathan's direct supervisor). It is clear from the case that the MIRR method was her strong preference, and also clear that decisions in the past were based on faulty analysis, since her assumed "benchmark" cost of capital had been used as long as the accountants could remember. However, Nathan would be well advised to avoid informing Natalie of her errors (nobody likes to be told they're wrong, especially if they are). While a variety of student responses to this dilemma may be forthcoming, we suggest a way that potentially maintains the integrity of the analysis and calms the potential storm from the change in decision process. We suggest that Nathan should calculate MIRR's for each of the accepted projects based on the proper rank ordering, and present this to Natalie as the optimal decision.

In the report to Natalie, Nathan should explain the optimizing methodology, dismissing the IRR method's decision as suboptimal, and position the rank ordering as the basis for determining proper MCC's for each of the projects in the maximizing permutation. He should base the MIRR calculations on these MCC's. The MIRR's are what Natalie expects in the report, after all. Nathan should not mention the prior practice of assuming a benchmark rate, since it is an incorrect method, unless someone challenges him about it. Instead, he should highlight the credit terms offered by the actual creditors supporting the capital budget. While this does not guarantee that no negative reactions occur, it might help to minimize the possibility.

Finally, Nathan might want to be prepared for the uninformed nay-sayer who uses Natalie's "benchmark" rate of $12.3 \%$ cost of capital to come up with the "decision" since it is possible someone might bring it up publicly (in front of Natalie). He might want to refer to the NPV implied by that method (presented earlier in the teaching note), and be prepared to show that it is not the maximum NPV decision.

The true NPV (using the actual $w M C C$ of .0713289) if only project B is accepted is $\$ 408,955$, obviously suboptimal. While we certainly do not support presenting incorrect processes or answers to students, professors may want to stress the possible errors that managers may make, and how Nathan should deal with that awkward situation in a sensitive (job-preserving) way. 


\section{Possible Use of "Leading Questions"}

For student groups that may need more guidance to reach the proper conclusions in the case, professors may wish to structure some "leading" questions: 1) What decision is implied by the IRR method using the arbitrary benchmark cost of capital? 2) Is the associated NPV optimal? 3) Why does the order in which projects are listed in the investment opportunity schedule important to assure maximizing the NPV? 4) What ordering of projects maximizes the NPV for the capital budget under consideration? 5) What are some of the politics involved with asserting a valid analysis, given the improper analyses performed in the past by Nathan's CFO?

It is at the professor's discretion to use these questions or their own series of questions to guide students through the thought process. For more advanced students, the professor may prefer to simply make the task to "solve the case."

\section{Note}

1 The authors would like to thank the following participants at the 2012 Financial Education Association meeting for insightful comments: Irv DeGraw, Jocelyn Evans, Robert Heller, Sivarama Krishnan, Thomas Musser, and Stephanie Smith.

\section{Biographical Sketches of Authors}

Dr. Robert Stretcher is a Professor of Finance at Sam Houston State University. He earned his $\mathrm{PhD}$ in Finance and Monetary Economics from The University of Tennessee. His research focuses on empirical market studies, applied finance, and finance education. Dr. Stretcher has held prominent positions in the Academy of Economics and Finance and the Institute of Finance Case Research, and has served on editorial boards and as editor of various finance journals.

Dr. Steve Johnson is an Assistant Professor of Finance at Sam Houston State University. He earned his PhD from The University of Utah. His research focuses on real options, applied finance and finance education. Dr. Johnson serves in various capacities in the Academy of Economics and Finance and is Managing Editor of the Journal of Instructional Techniques in Finance.

Dr. Mary Funck is an Assistant Professor of Finance at Sam Houston State University. She earned her PhD from The University of Mississippi. Her research focuses on market microstructure, applied finance and finance education. 